\title{
Politique
}

Politique

\section{Marc LESAGE et Francine TARDIF (Eds), 30 ans de Révolution \\ tranquille, itinéraires et mouvements, Montréal, Éd. \\ Bellarmin, 1989, 223 p.}

\section{Paule Duchesneau}

Numéro 17, hiver 1990

Les nouveaux enjeux du politique

URI : https://id.erudit.org/iderudit/040654ar

DOI : https://doi.org/10.7202/040654ar

Aller au sommaire du numéro

Éditeur(s)

Société québécoise de science politique

ISSN

0711-608X (imprimé)

1918-6584 (numérique)

Découvrir la revue

Citer ce compte rendu

Duchesneau, P. (1990). Compte rendu de [Marc LESAGE et Francine TARDIF

(Eds), 30 ans de Révolution tranquille, itinéraires et mouvements, Montréal, Éd.

Bellarmin, 1989, 223 p.] Politique, (17), 162-164.

https://doi.org/10.7202/040654ar d'utilisation que vous pouvez consulter en ligne.

https://apropos.erudit.org/fr/usagers/politique-dutilisation/ 
Marc LESAGE et Francine TARDIF (Eds), 30 ans de Révolution tranquille, itinéraires et mouvements, Montréal, Éd. Bellarmin, 1989, $223 \mathrm{p}$.

Ce recueil de textes présenté à l'été 1989 , lors d'un colloque organisé par la revue Relations et le Centre justice et foi, regroupe la contribution de seize panelistes qui posent un regard sur la Révolution tranquille. C'est à travers leur histoire de vie qu'ils se partagent quatre thèmes: «L'Âme, du catholicisme dominant à la production de nouveaux dieux; L'Héritage, de la soumission au devoir au règne du plaisir; La Cité, des luttes collectives à l'affirmation de l'individu et Le Pays, du beau rêve d'un État québécois émancipateur à la gestion difficile d'une société incertaine». Un bref survol des thèmes abordés démontrera l'intérêt de chacun d'entre eux.

Avec le thème de «l'Âme» s'entrecroisent modernité, sécularisation, démocratie, structures. Mgr Bertrand Blanchet traite de la modernisation de l'Église qui s'est faite simultanément à celle de l'État, sans heurts, comme en parallèle: le concile d'une part, l'État-providence de l'autre. Renouvellement des valeurs et solidarité sont à surveiller. Plutôt désenchantée, Louise Gagné parle de la révolution à parfaire via la question des transformations de la vie communautaire. Il n'y a pas eu de changements réels dans les structures. Si la révolution fut tranquille, c'est que les mentalités n'ont pas réellement changé. La révolution est à compléter mais les enjeux et les malaises sociaux sont maintenant différents. Suzanne Rousseau fait un bilan de son cheminement spirituel, qui l'a conduite d'un catholicisme autoritaire à un engagement libre et responsable. Fondatrice du Groupe d'Eve-à-nous, elle témoigne du vécu des femmes engagées dans l'Église et confrontées aux structures en place. Joseph Giguère pose les problèmes de la rupture et de la discontinuité face à l'héritage catholique et à la modernité. Il constate que la révolution démocratique n'a pas eu lieu: les structures institutionnelles sont demeurées, l'option pour les pauvres a été évacuée.

«L'Héritage» regroupe les idées de valeurs, de diversité et de pluralité. André Ricard examine la communauté, le vouloir-vivre 
collectif. Il se sent un naufragé de la Révolution tranquille, d'un pays inachevé où le discours économique a supplanté le discours nationaliste, où la multiethnicité redéfinit l'identité. Gisèle Turcot s'interroge sur le choix et se demande: était-il bon? À travers les domaines sociaux et religieux elle évoque la modernité de l'État et de l'Église. La planification a sapé l'héritage: déplacement institutionnel, dispersion des équipes communautaires, essoufflement des communautés religieuses. L'héritage est banalisé. Jean-Claude Icart nous relate son arrivée au Québec et traduit la diversité ethnique comme l'un des plus importants héritages de la Révolution tranquille: «Le Québec s'ouvre sur le monde et le monde entre au Québec [103]». La «démolinguistique» traduit le Québec d'aujourd'hui, francophone et multiethnique. Hubert Guindon nous fait réfléchir sur l'aujourd'hui. Il se demande comment se vivent le français et le binlinguisme. Pour lui, la Révolution tranquille a mis l'Église à sa place et a donné toute la place aux Québécois. Il note l'intransigeance de ceux qui ont bénéficié de cette révolution et la banalisation du mouvement national.

La «Cité» interpelle les acteurs, les valeurs, la mobilisation. Marcel Pépin fait un appel à la mobilisation. Il constate que «l'action collective et solidaire fait place à l'action individuelle», et invite la nation à s'unir pour pouvoir progresser. Claire Bonenfant situe l'histoire du mouvement des femmes dans la mouvance de la Révolution tranquille. Elle note la montée et la transformation du féminisme; elle constate le passage de la théorie à l'action; elle parle de l'émergence des réseaux professionnels. Selon Bonenfant, les illusions demeurent présentes, bien que de nouveaux modèles restent à proposer. Suzanne Laferrière décrit les malaises des milieux ouvriers où se retrouvent de nombreux groupes communautaires. Elle insiste sur la détérioration du mode de vie de ces milieux, exclus des bienfaits de la Révolution tranquille, dans lesquels l'action communautaire a été profondément transformée. Normand Ricard apporte le point de vue de l'entrepreneur québécois, dynamique et plein d'espoir. Son projet de pays se situe dans l'avancée économique du Québec. Aujourd'hui, note-t-il, l'individu s'ouvre au monde, à l'environnement, à sa société. Ce faisant, il ne doit pas oublier la collectivité et le partage. 
Le «Pays», c'est la mutation vers de nouveaux enjeux, c'est la déception. Julien Harvey trace un bilan personnel du pays inachevé. Il réfléchit sur les joies et les difficultés de vivre dans un pays incertain: la Révolution tranquille, la prise du pouvoir par le $P Q$, les résultats décevants du référendum. Céline Saint-Pierre voit le pays à travers son militantisme dans les associations catholiques et par le biais de son adhésion au socialisme. La mise en place d'un État moderne, sécularisé, rationnel, a porté ombrage aux groupes et aux syndicats. La question du pays n'est plus la même. «Les problèmes sociaux prennent le dessus sur la question nationale» dit-elle (p. 191). Jean Robitaille montre que la Révolution tranquille est terminée. Le Québec est en mutation; les complicités s'estompent, les valeurs sont à revoir. Les défis sont différents et il conclut que le Québec a besoin de nouveaux leaders. Denis Vaugeois aborde les problèmes de la démographie, de l'immigration, du territoire. Il s'inquiète des institutions démocratiques. «On dirait que la léthargie qui a frappé le parlement est à l'image du demi-sommeil qui a caractérisé tout le Québec au cours des dernières années» (p. 205). Pour lui, la vraie question est la suivante: «Pourra-t-on par ailleurs éviter de verser dans la médiocrité et l'ennui?» (p. 206).

Bien que d'un intérêt certain, cet ouvrage est toutefois de qualité inégale, comme c'est souvent le cas dans un recueil de textes. L'histoire du Québec des 30 dernières années se déroule à travers les états d'âme de chacun, au fil des joies et des peines qu'ils ont connues. Les commentaires de Marie Gratton-Boucher et de Alain Touraine sur chacun des thèmes traités sont pertinents et enrichissent le débat. La révolution est-elle achevée ou inachevée? Somme-nous enchantés ou désenchantés? Où en sommes-nous aujourd'hui? Les ambivalences et les assurances se rencontrent, se mêlent et se démêlent. 30 ans de Révolution tranquille est un livre à lire pour ceux et celles qui veulent appréhender 30 ans d'histoire du Québec par le biais de la mémoire sélective de certains acteurs.

Au fait, la Révolution tranquille a-t-elle duré 30 ans?

Paule Duchesneau Université Laval 